Xin Jiang, Jianhua Shu, Hongying Xia, Libo Zhang* and Jinhui Peng

\title{
Regeneration of spent mercury catalyst for the treatment of dye wastewater by the microwave and ultrasonic spray-assisted method
}

https://doi.org/10.1515/gps-2018-0077

Received April 10, 2018; accepted July 20, 2018; previously published online September 7, 2018

\begin{abstract}
Large amounts of spent mercury catalyst (SMC) produced in producing polyvinyl chloride (PVC) has a great influence on the environment. In this work, microwave and ultrasonic spray were applied to regenerate the carrier of SMC. The optimal experimental conditions were the regeneration temperature of $900^{\circ} \mathrm{C}$ and regeneration time of $60 \mathrm{~min}$. Subsequently, the textures of pores and mercury content, morphology structure and surface functional groups of SMC and the regenerated activated carbon (RAC) were characterized by $\mathrm{N}_{2}$ adsorption and desorption isotherms, ICP, SEM, EDS and FTIR. Additionally, the adsorption behaviors of RAC on methylene orange (MO) and congo red (CR) were explored to study the mechanisms. The results of kinetics and isotherm showed that experimental data were fitted well with the pseudo second-order and Langmuir isotherm model, respectively. The maximum adsorptions of MO and CR were 529 and $301 \mathrm{mg} / \mathrm{g}$ at $323 \mathrm{~K}$. The thermodynamic results illustrated that the adsorption MO and CR onto RAC was spontaneous and endothermic. The results demonstrated that RAC prepared from SMC by
\end{abstract}

*Corresponding author: Libo Zhang, State Key Laboratory of Complex Nonferrous Metal Resources Clean Utilization, Kunming University of Science and Technology, Kunming, Yunnan 650093, China; Yunnan Provincial Key Laboratory of Intensification Metallurgy, Kunming University of Science and Technology, Kunming, Yunnan 650093, China; National Local Joint Laboratory of Engineering Application of Microwave Energy and Equipment Technology, Kunming, Yunnan 650093, China; and Faculty of Metallurgical and Energy Engineering, Kunming University of Science and Technology, Kunming, Yunnan 650093, China, e-mail: zhanglibopaper@126.com

Xin Jiang, Jianhua Shu, Hongying Xia and Jinhui Peng: State Key Laboratory of Complex Nonferrous Metal Resources Clean Utilization, Kunming University of Science and Technology, Kunming, Yunnan 650093, China; Yunnan Provincial Key Laboratory of Intensification Metallurgy, Kunming University of Science and Technology, Kunming, Yunnan 650093, China; National Local Joint Laboratory of Engineering Application of Microwave Energy and Equipment Technology, Kunming, Yunnan 650093, China; and Faculty of Metallurgical and Energy Engineering, Kunming University of Science and Technology, Kunming, Yunnan 650093, China

Ә Open Access. (c) BY $\odot 2019$ Walter de Gruyter GmbH, Berlin/Boston microwave heating and ultrasonic spray could realize the comprehensive utilization of waste resources.

Keywords: adsorption behavior; microwave heating; regenerated activated carbon; ultrasonic spray.

\section{Abbreviations}

$\begin{array}{ll}\text { BET } & \text { Brunauer-Emmett-Teller } \\ \text { CR } & \text { congo red } \\ \text { DFT } & \text { Density Functional Theory } \\ \text { MB } & \text { methylene blue } \\ \text { MO } & \text { methylene orange } \\ \text { PVC } & \text { polyvinyl chloride } \\ \text { R }^{2} & \text { correlation coefficient } \\ \text { RAC } & \text { regenerated activated carbon } \\ \text { SMC } & \text { spent mercury catalyst } \\ \text { VCM } & \text { vinyl chloride monomer. }\end{array}$

\section{Introduction}

Polyvinyl chloride (PVC) is the most commonly used thermoplastic resin [1], following polyethylene and polypropylene. At the same time, the global demand keeps on increasing [2], and PVC products can now be manufactured into hard products. In addition, it plays an important role in the fields of industry, agriculture, national defense and building owing to its low cost, persistence and excellent physico-chemistry properties [3-5]. Vinyl chloride monomer (VCM) is mainly used for PVC synthesis, and the preparation technology of PVC is distinctive in China [6-8]. As a catalyst for the composition of VCM, large numbers of mercuric chloride catalyst are applied in PVC industries [9]. Therefore, a large amount of spent mercury catalyst (SMC) is produced due to the final loss and deactivation [10]. SMCs contain trace amounts of mercury, and any form of mercury is considered as toxic [11]. Mercury-containing wastes pose potential threats to the living environment, the central nervous system of organisms and vital organs [12-15]. Consequently, there is an urgent need to find an effective way to deal with SMC. Acetylene hydrochlorination is an important coal process for manufacturing vinyl chloride on a commercial scale, particularly in developing countries, such as China and India, where coal 
reserves are abundant but oil is lacking $[8,16]$. According to the energy structure, most mercury catalysts are based on the coal-based activated carbon, that is to say, mercuric chloride is loaded on the activated carbon [17]. Acetylene hydrochlorination has been largely replaced by ethanebased process in many developed countries, but it is still used in locations where coal resources are relatively rich. Therefore, the production of VCM mainly takes mercuric chloride as a catalyst in our country. Over a period of time, the mercuric chloride catalyst is deactivated and becomes SMC. Due to the dissolution, consumption and heating sublimation during application, the mercury content in SMC is very low, making itit difficult to recover mercury [18]. However, the activated carbon loaded on the catalyst has excellent adsorption performance, so it is very meaningful to regenerate SMC to obtain activated carbon.

The mercury chloride catalysts are deactivated after use, the pore channels of support activated carbon are blocked, so it is necessary to restore the pore structure of activated carbon by regeneration methods. At present, the regeneration methods of activated carbon are widely used at home and abroad, including thermal regeneration [19], biological regeneration, ultrasonic regeneration, microwave regeneration [20] and wet oxidation processes [21]. Recently, the use of microwave heating to regenerate the spent activated carbon was mentioned in some studies [22]. Compared with the conventional thermal regeneration technology, microwave regeneration could save time and energy to obtain high extraction efficiency and operate easily and conveniently [23]. Moreover, the activated carbon was heated internally and has good microwave adsorption properties. The heat and energy generated through highfrequency internal dipole rotation directly penetrate into the activated carbon during microwave heating process. Furthermore, some past studies have mentioned that the regenerated activated carbon (RAC) via microwave heating method can develop new pore structures and increase surface area [24-26]. Accordingly, microwave regeneration can accelerate the efficiency and have good effects on spent activated carbon, which can effectively remove the adsorbed pollutants. In addition, the ultrasonic spray can be induced during the regeneration process. Compared with the conventional high temperature steam, ultrasonic spray can be generated through the ultrasonic device at normal temperature. Therefore, microwave heating combined with ultrasonic spray can reduce the energy output [20].

In the current study, SMC produced in PVC production was regenerated by the combination of microwave heating and ultrasonic spray. Different experimental conditions have great influence on MB adsorption capability and RAC yield. The SMC and RAC were characterized by various technologies. Furthermore, the adsorption behavior of RAC was explored with methylene orange (MO) and congo red (CR) as pollutants. The findings of this study can be used for further understanding of the treatment effect of microwave heating and ultrasonic spray and comprehensive use of waste resources.

\section{Materials and methods}

\subsection{Materials}

The SMCs used in this work were obtained from a chemical plant for producing PVC (Huize, Yunnan, China). The mercury catalyst supported activated carbon was prepared by coal and used as raw material, which presented columnar particles. All chemical reagents, such as $\mathrm{HCl}, \mathrm{NaCl}$ and $\mathrm{HNO}_{3}$ were purchased from Tianjin Reagent Chemicals Co. Ltd., Tianjin, China. All materials were used in this study without further purification. The chemical properties of MO and CR are shown in Table 1.

Table 1: The properties of $M O$ and CR.

\begin{tabular}{lll}
\hline Dye & Parameters & Chemical structure \\
MO & Chemical formula & \\
Molecular weight & Chemical structure \\
CR & Molecular weight & \\
& &
\end{tabular}




\subsection{Regeneration of SMC}

Experiments were carried out in a self-made microwave furnace (Key Laboratory of Unconventional Metallurgy, Kunming University of Science and Technology, Kunming, Yunnan, China). The frequency of microwave oven was $2.5 \mathrm{GHz}$ and the power intensity was $1000 \mathrm{~W}$. A certain amount of SMC was placed into microwave oven, in which $\mathrm{N}_{2}$ with a purity of $99.9 \%$ was discharged at $100 \mathrm{l} / \mathrm{h}$, and the flow rate of ultrasound spray was $30 \mathrm{l} / \mathrm{h}$. During the regeneration experiments, different parameters of microwave oven were set to get different samples. The obtained RAC was placed inside a vacuum drying oven at $85^{\circ} \mathrm{C}$ for $3 \mathrm{~h}$ and then crushed These were then stored in sealed bags for further characterization. To prevent harmful gas leakage, the solution adsorption was used to treat the exhaust gas. The experimental device diagram was showed in Figure 1.

\subsection{Characterization of SMC and RAC}

Samples of SMC and RAC were characterized by various techniques as described below. The yield $(Y)$ of RAC was calculated using the following formula:

$$
Y=\frac{W_{1}}{W_{2}} \times 100 \%,
$$

where $W_{1}$ and $W_{2}$ are the weights of RAC and SMC, respectively. The MB adsorption capacity was determined using the Standard Testing Methods of PR China (GB/T 7702.6-2008) [27]. The pore and textural properties were characterized at $77 \mathrm{~K}$ (Quant chrome, Autosorb-1-C). Before the gas adsorption test, the samples were degassed at $300^{\circ} \mathrm{C}$ for $10 \mathrm{~h}$ under vacuum condition. The surface area was calculated using the Brunauer-Emmett-Teller (BET) equation, and the pore size distribution was analyzed using the Density Functional Theory (DFT) model. The total pore volumes were evaluated at the relative pressure of 0.99 , which was the equivalent liquid volume of nitrogen. The surface texture and morphology was observed by a SEM
(Phenom-World-ProX, the Netherlands), which equipped with EDS (Phenom-World-ProX, the Netherlands) under an acceleration voltage of $15 \mathrm{KV}$. FTIR was used to observe the functional groups by using a NicoletiS10 spectrophotometer (Thermo Fisher Scientific, USA). The FTIR spectra were obtained between 4000 and $400 \mathrm{~cm}^{-1}$.

\subsection{Determination of mercury content}

The mercury content was determined using the Standard Testing Methods of PR China (GB/T31530-2015) [18]. About $1 \mathrm{~g}$ SMC and RAC was placed into a 250-ml Erlenmeyer flask, to which $15 \mathrm{ml}$ of $\mathrm{HCl}$, $5 \mathrm{ml}$ of $\mathrm{HNO}_{3}$ and $20 \mathrm{ml}$ of $100 \mathrm{mg} / \mathrm{l} \mathrm{NaCl}$ solution. The solution was heated to boiling for $15 \mathrm{~min}$ and then cooled to room temperature, which was diluted with distilled water to $500 \mathrm{ml}$. The blank experiment was also carried out. The mercury concentration in the filtrate was determined by inductively coupled plasma optical emission spectrometry (ICP-OES, Thermo Scientific iCAP 7200).

\subsection{Adsorption study}

The adsorption capacity of RAC was determined by using MO and CR as organic pollutants, which carried were out in a thermostatic oscillator that the temperature ranges between $303 \mathrm{~K}$ and $323 \mathrm{~K}$. The MO and CR solution were prepared by diluting the $1000 \mathrm{mg} / \mathrm{l} \mathrm{MO}$ and CR solution with distilled water. One hundred milliliter MO solution and CR solution were added into 250-ml Erlenmeyer flasks with $0.05 \mathrm{~g}$ RAC, respectively. The remaining concentration of $\mathrm{MO}$ and CR solution were tested by UV-vis spectrophotometer (Shimadzu UV2600). To obtain the equilibrium concentration, Erlenmeyer flasks were placed in the thermostatic oscillator with shaking speed of $250 \mathrm{rpm}$ for $5 \mathrm{~h}$. The equilibrium concentration was used in the following tests. The equilibrium adsorption capacity $\left(q_{e}, \mathrm{mg} / \mathrm{g}\right)$ is calculated according to Equation (2)

$$
q_{e}=\frac{\left(C_{0}-C_{e}\right) \times V}{m},
$$

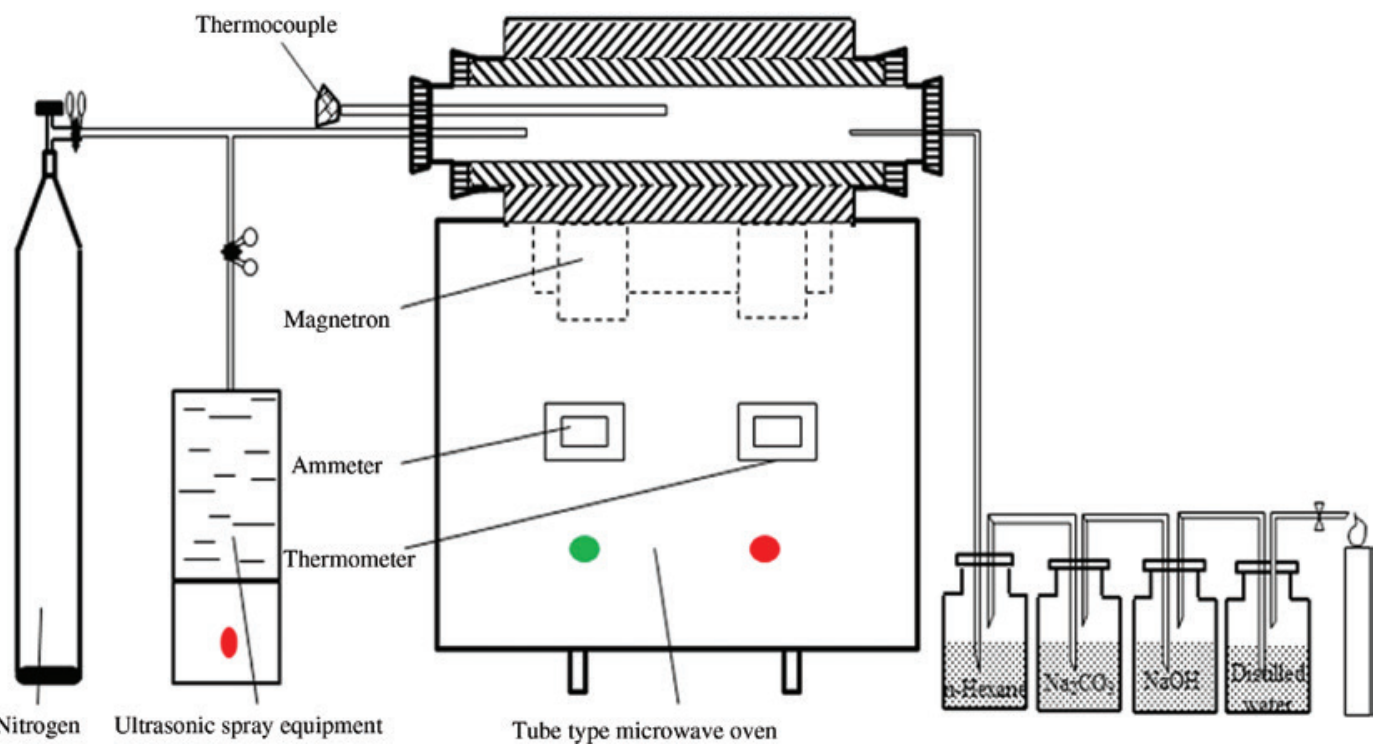

Figure 1: The diagram of the experimental setup. 
where $C_{0}$ and $C_{e}$ are the initial concentration and equilibrium concentration $(\mathrm{mg} / \mathrm{l})$, respectively, $V$ is the volume of the dye solution $(\mathrm{ml})$ and $m$ is the mass of RAC (g).

\section{Results and discussion}

\subsection{Effect of regeneration temperature on MB value and yield of RAC}

Regeneration temperature was a significant parameter. The effect of regeneration temperature on $\mathrm{MB}$ value and yield of RAC was investigated when the temperature was in the range from $500^{\circ} \mathrm{C}$ to $900^{\circ} \mathrm{C}$ and regeneration time was $60 \mathrm{~min}$. As shown in Figure 2, the overall trend of the MB value increased and the yield declined. The MB value reached to a maximum of $210 \mathrm{mg} / \mathrm{g}$ when the regeneration temperature was $900^{\circ} \mathrm{C}$. This can be explained as follows: the small part of the pores were constructed when the regeneration temperature was low. The MB value increased along with the increase of temperature. It was clearly revealed that some substances in SMC were volatilized and decomposed under nitrogen atmosphere and ultrasonic spray and more pores formed. Thus, the pore channel of activated carbon can be restored with microwave heating and ultrasonic spray. A temperature of $900^{\circ} \mathrm{C}$ was selected and used for the following experiments.

\subsection{Effect of regeneration time on MB value and yield of RAC}

The effects of regeneration time on MB value and yield of RAC was investigated under a regeneration temperature of

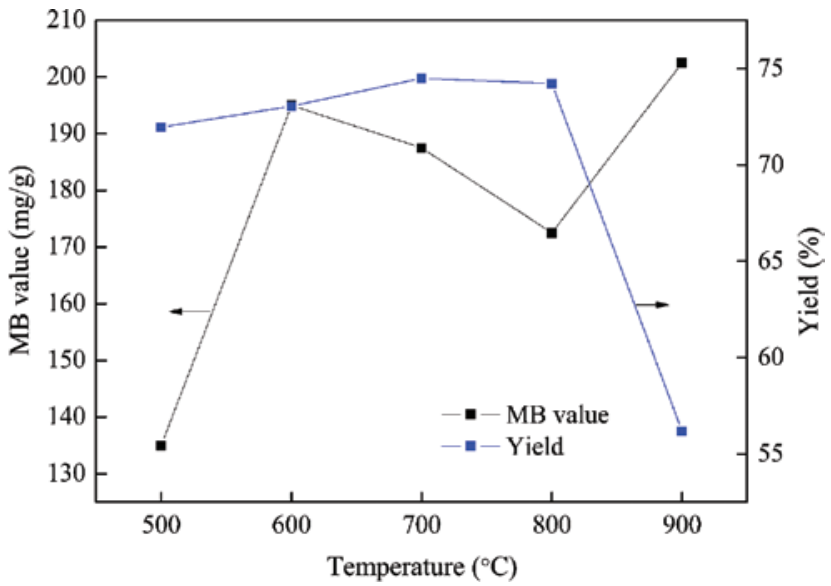

Figure 2: The effect of regeneration temperature on MB value and yield of RAC.

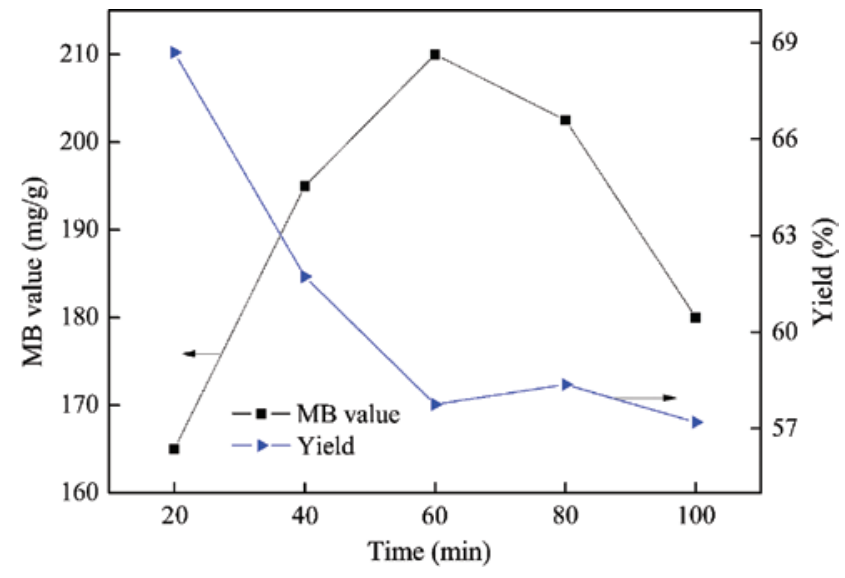

Figure 3: The effect of regeneration time on MB value and yield of RAC.

$900^{\circ} \mathrm{C}$. As shown in Figure 3, the MB value increased firstly and then decreased with the increase of regeneration time. This can be attributed to the fact that the increase of regeneration time was beneficial to the volatilization of the adsorbed substances in SMC. However, with the extension of regeneration time, the MB value decreased gradually. Exceeding a certain time, the pores of RAC would be damaged and the surface will be burned. Considering comprehensively, $60 \mathrm{~min}$ was selected as the regeneration time. According to the above analysis, the optimum conditions of regeneration experiments included $900^{\circ} \mathrm{C}$ of regeneration temperature and $60 \mathrm{~min}$ of regeneration time.

\subsection{Textural characteristics and mercury content}

Figure 4 shows the $\mathrm{N}_{2}$ adsorption-desorption isotherms of the SMC and RAC samples. According to the IUPAC classification, both isotherms can be classified to be a type IV [28]. When the relative pressure was between 0.4 and 0.9 , both samples exhibited hysteresis loops. The $\mathrm{N}_{2}$ adsorption-desorption isotherm of RAC presented a wider hysteresis loops than that of SMC due to the capillary condensation occurred. The pore structure details and mercury content of two samples were listed in Table 2. The obtained RAC possessed a specific surface area $\left(801.6 \mathrm{~m}^{2} / \mathrm{g}\right)$ and total pore volume that was comparatively higher to SMC. It can be explained that the combination of microwave heating and ultrasonic spray was beneficial to develop new gaps. The average pore size of RAC was estimated to be $1.08 \mathrm{~nm}$, which was lower than before regeneration, indicating that microporous morphology of RAC. Furthermore, the mercury contents of SMC and RAC 


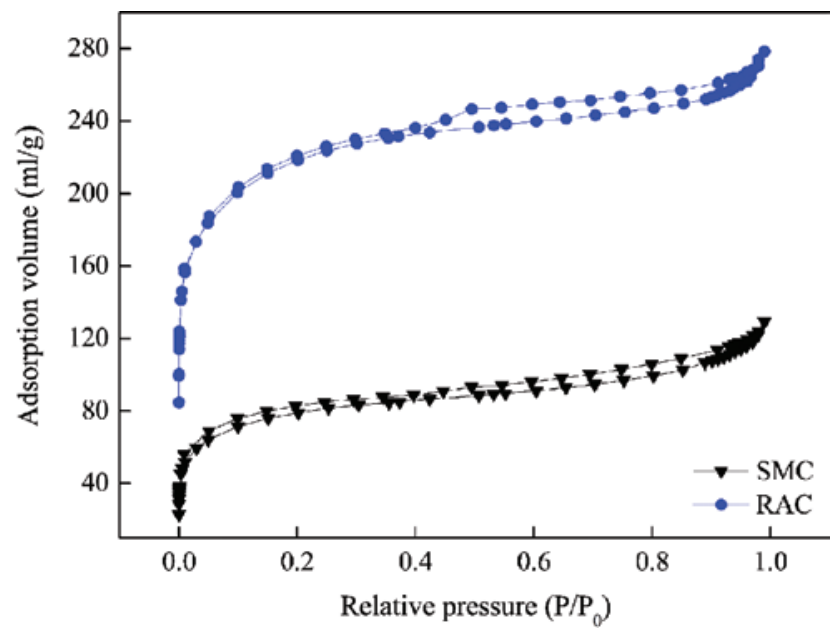

Figure 4: The $\mathrm{N}_{2}$ adsorption isotherm of SMC and RAC.

Table 2: The pore structure details and mercury contents of SMC and RAC.

\begin{tabular}{lrr}
\hline Characteristic & \multicolumn{1}{c}{ SMC } & RAC \\
\hline Specific surface area $\left(\mathrm{m}^{2} / \mathrm{g}\right)$ & 239.8 & 801.6 \\
Total pore volume $(\mathrm{ml} / \mathrm{g})$ & 0.20 & 0.43 \\
Average pore size $(\mathrm{nm})$ & 2.78 & 1.08 \\
Mercury content $(\mathrm{mg} / \mathrm{l})$ & 23.70 & 0.46 \\
\hline
\end{tabular}

were 23.70 and $0.46 \mathrm{mg} / \mathrm{l}$. It can be explained that the mercuric chloride easily sublimated and evaporated at a high temperature, and most of the mercury was taken away under the atmosphere of $\mathrm{N}_{2}$ and ultrasonic spray. Through experimental data analysis, the microwave and ultrasonic spray-assisted regeneration of SMC can effectively develop a new pore structure.

\subsection{SEM and EDS analysis}

The SEM was carried out to evaluate the surface morphology and texture of materials [29]. As can be seen in Figure 5A, the surface of SMC was relatively rough and irregular and there was no apparent pore structure. After regeneration (Figure 5B), the surface of RAC appeared obvious pore structure and the impurities on the surface of the activated carbon reduced. As can be seen from the EDS results (Figure 6), there was almost no mercury on the surface of RAC, proving that the mercury was effectively removed. This result is consistent with the determination of mercury content. Therefore, microwave heating and ultrasonic spray-assisted regeneration of activated carbon was an effective method.

\subsection{FTIR analysis}

The FTIR technique was used to examine the important functional groups existed on the surface of SMC and RAC (Figure 7). As can be seen from Figure 7, the FTIR spectra of the two samples are roughly similar [30]. Both samples had a same clear high intense peak at $3433 \mathrm{~cm}^{-1}$, and this may be water and existed $\mathrm{O}-\mathrm{H}$ and $\mathrm{N}-\mathrm{H}$ stretching vibration, respectively. The peak around $2924 \mathrm{~cm}^{-1}$ corresponded to the stretching vibration of the $\mathrm{C}-\mathrm{H}$ group and caused by $\mathrm{CO}_{2}$ in the air. The band fund at $2852 \mathrm{~cm}^{-1}$ can be assumed as the $\mathrm{C}-\mathrm{H}$ group. The absorption peak at about $2340 \mathrm{~cm}^{-1}$ was the asymmetric expansion vibration absorption of carbon dioxide. The peak at $1636 \mathrm{~cm}^{-1}$ can be attributed to the aromatic $\mathrm{C}=\mathrm{C}$ bond. The symmetric bending of $\mathrm{CH}_{3}$ was detected in the peak with approximate maximum around $1457 \mathrm{~cm}^{-1}$ [31]. The peak at about $1100 \mathrm{~cm}^{-1}$ was attributed to the $\mathrm{C}-\mathrm{O}$ bond. The peak at
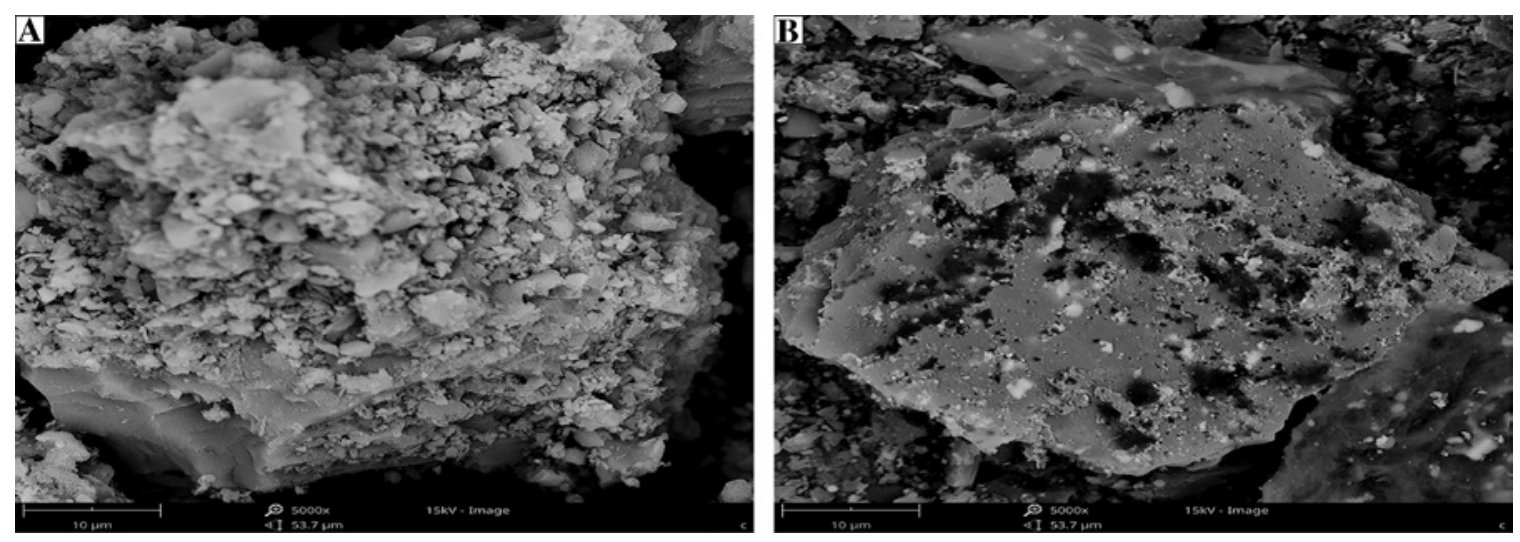

Figure 5: The SEM micrographs of SMC (A), RAC (B). 
A

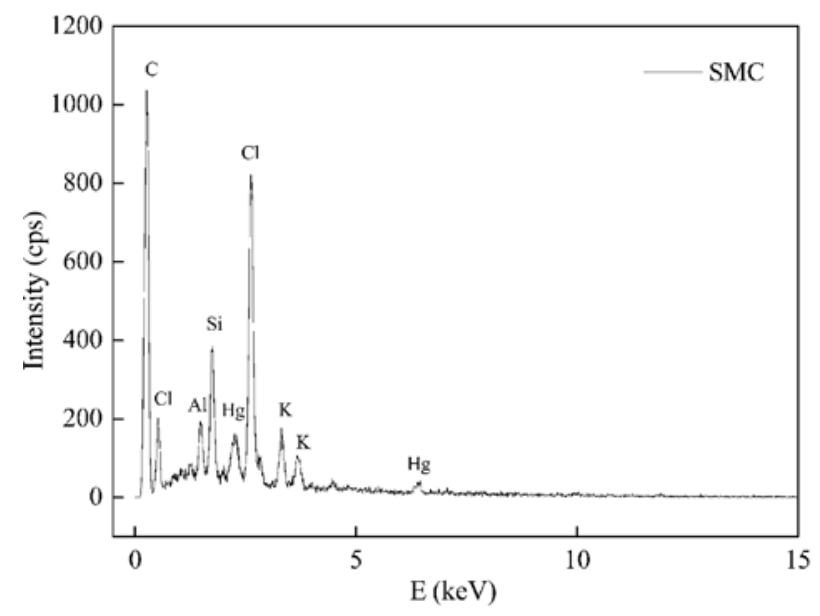

Figure 6: The EDS images of SMC (A), RAC (B).

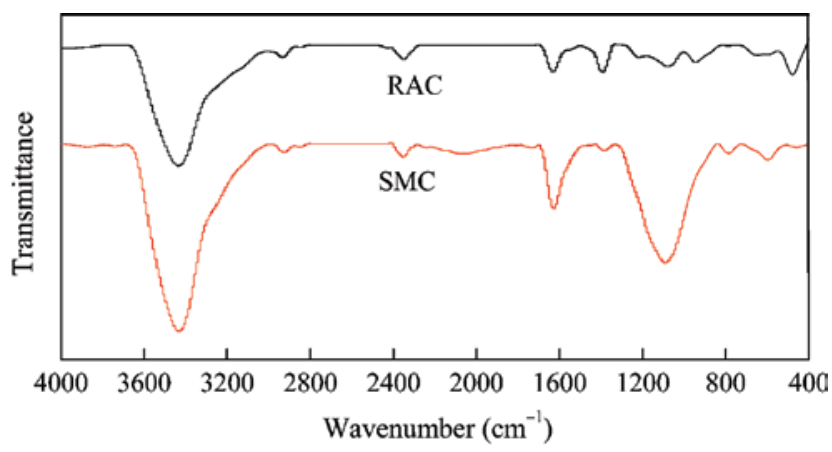

Figure 7: The FTIR spectra of SMC and RAC.

about $400-800 \mathrm{~cm}^{-1}$ corresponded to vibrations of iron and zinc compounds [32]. It can be seen that SMC has a stronger vibrational peak at 1100 and $1636 \mathrm{~cm}^{-1}$, which can indirectly prove that the functional groups on RAC have

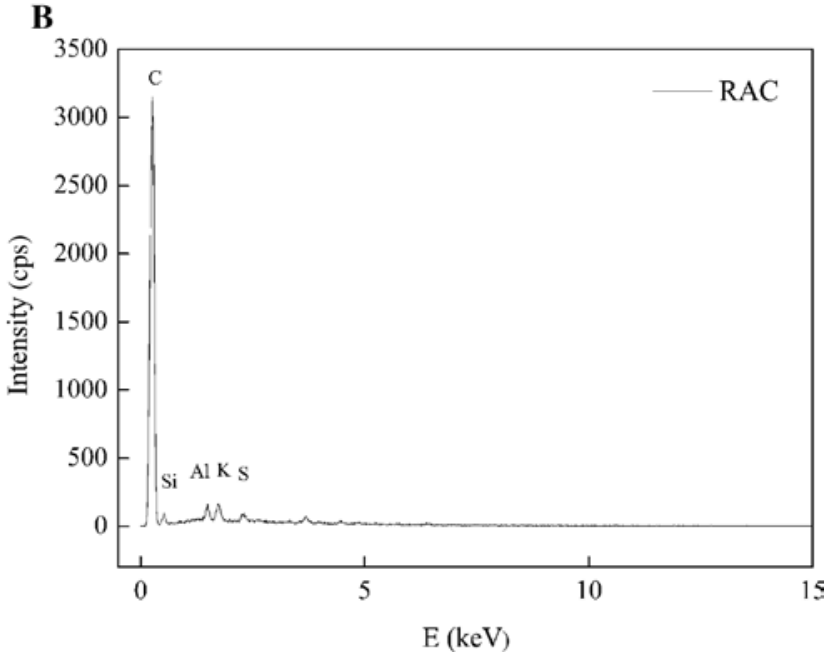

been weakened and some substances have been effectively removed.

\subsection{Adsorption kinetics}

To check the mechanism of adsorption, the kinetic experiments were performed using $0.05 \mathrm{~g}$ RAC with $100 \mathrm{ml}$ MO and CR solution at $313 \mathrm{~K}$. The removal efficiencies of the $\mathrm{MO}$ and CR solution with different initial concentrations were investigated. The results are presented in Figure 8. It can be found that the removal efficiency of MO and CR solution almost reached equilibrium at $100 \mathrm{~min}$. Three models of pseudo first-order, pseudo second-order and intra-particle diffusion were employed to obtain the important parameters, respectively. The correlation coefficients $\left(R^{2}\right)$ were used to evaluate the conformity
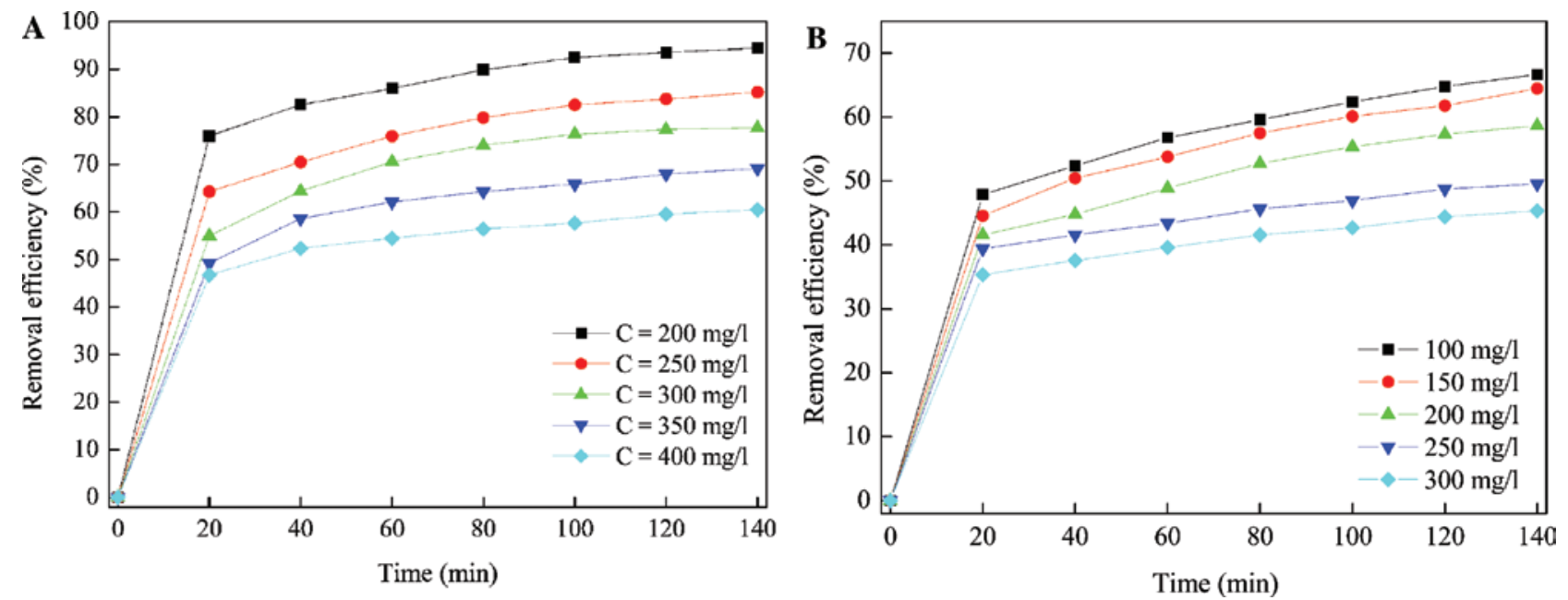

Figure 8: The removal efficiencies of the $M O(A)$ and $C R(B)$ solution with different initial concentrations at $313 \mathrm{~K}$. 
Table 3: Kinetic parameters for adsorption of $M O$ and CR adsorption onto RAC.

\begin{tabular}{|c|c|c|c|c|c|c|c|c|c|}
\hline \multirow[t]{2}{*}{ Dye } & \multicolumn{3}{|c|}{ Pseudo first-order } & \multicolumn{3}{|c|}{ Pseudo second-order } & \multicolumn{3}{|c|}{ Intra-particle diffusion } \\
\hline & $k_{1}$ & $q_{t}$ & $\mathbf{R}^{2}$ & $k_{2}$ & $q_{e}$ & $\mathbf{R}^{2}$ & $\boldsymbol{k}_{\mathrm{dif}}$ & c & $\mathbf{R}^{2}$ \\
\hline MO & 0.0151 & 60.6 & 0.979 & 0.0007 & 469.4 & 0.999 & 4.83 & 405.2 & 0.996 \\
\hline CR & 0.0172 & 134.1 & 0.985 & 0.0003 & 324.7 & 0.997 & 22.8 & 172.8 & 0.979 \\
\hline
\end{tabular}

between the experimental data and the model predicted values. [33]:

The pseudo first-order can be expressed as follows (3)

$$
\ln \left(q_{e}-q_{t}\right)=\ln q_{e}-k_{1} t
$$

where $q_{t}$ was the adsorption capacity at time $t(\mathrm{mg} / \mathrm{g})$, the $k_{1}$ is the rate constant $[\mathrm{g} /(\mathrm{mg} \cdot \mathrm{min})]$.

The pseudo second-order model can be illustrated according the following equation (4) [34]:

$$
\frac{t}{q_{t}}=\frac{t}{q_{e}}+\frac{1}{\left(k_{2} \times q_{e}^{2}\right)},
$$

where $k_{2}$ is the rate constant $[\mathrm{g} /(\mathrm{mg} \cdot \mathrm{min})]$.

The intra-particle diffusion model can be defined by the following equation (5) [35]:

$$
q_{t}=k_{\mathrm{dif}} \times \sqrt{t}+c,
$$

where $k_{\text {dif }}$ is the intra-particle diffusion rate constant $(\mathrm{mg} /$ $\left(\mathrm{g} \cdot \mathrm{min}^{1 / 2}\right)$, and $c$ is the intercept $(\mathrm{mg} / \mathrm{g})$ relating to the thickness of boundary layer.

The obtained kinetic parameters were given in Table 3. As can be seen, the values of $\mathrm{R}^{2}$ for three kinetic models are satisfactory. However, the adsorption process of MO and CR can be described with pseudo second-order due to the values of $\mathrm{R}^{2}$ were close to 1 and the calculated adsorption values were consistent with the experimental data. The pseudo second-order indicated that the chemisorption played an important role in the rate limiting step [36], where the dye molecules attached to the surface of RAC by the transferring or sharing of the electron [37]. The adsorption was a complex process. Although the experimental data fitted well with pseudo second-order, the results obtained from this model could not predicate the diffusion process. Furthermore, two steps were studied. The first stage mainly depended on the surface pore structures of RAC. The adsorption appeared to be easing in the second stage due to the intraparticle diffusion was a rate-limiting process. In general, the fitted line passed through origin, which indicated that the pore diffusion controlled the adsorption processes. As can be seen the data in Table 3, both lines did not pass through the origin. This explains that the transfer rates in two stages are not consistent. It confirmed that the intraparticle diffusion was not the only rate-limiting step. Similar results have been reported in previous literatures [38]. The pseudo second-order for MO and CR adsorption was showed in Figure 9.

\subsection{Adsorption isotherm}

The adsorption equilibrium isotherm can reveal the status of the adsorbate and adsorbent at a confirmed temperature. The isotherm studies were conducted with the MO and CR solution with initial concentration of $200-400 \mathrm{mg} / \mathrm{l}$ and $100-300 \mathrm{mg} / \mathrm{l}$. The adsorption process was conducted at the temperature of $303 \mathrm{~K}, 313 \mathrm{~K}$ and $323 \mathrm{~K}$. Three isotherm equations were considered to study the mechanism and calculate the maximum adsorption capacity.

The Langmuir isotherm is applied in the following form (6) [39]:

$$
\frac{1}{q_{e}}=\frac{1}{q}+\frac{1}{C_{e} \times K_{L}},
$$

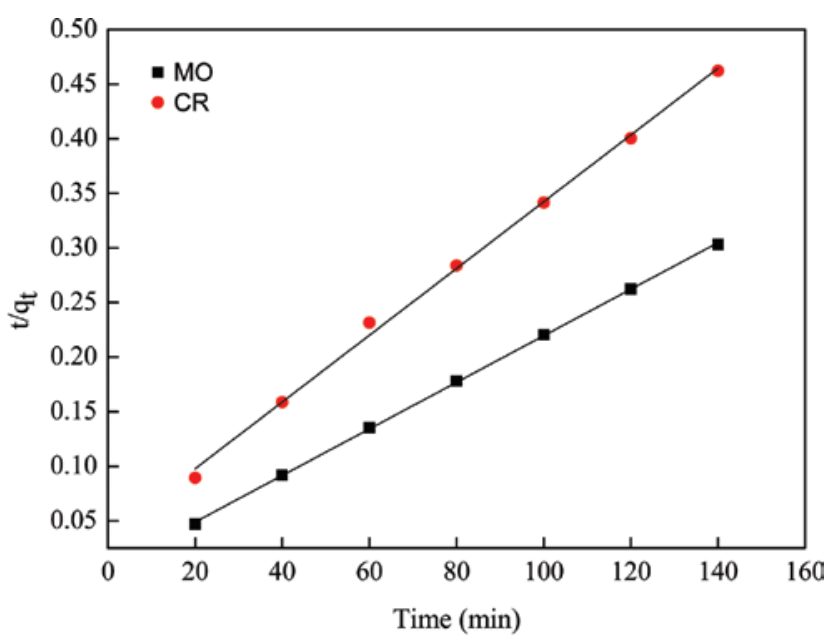

Figure 9: The experimental data fitting analysis by pseudo secondorder model for $\mathrm{MO}$ and $\mathrm{CR}$ dye solution. 
Table 4: The isotherm constants for adsorption of the $M O$ and CR dye solution onto RAC.

\begin{tabular}{|c|c|c|c|c|c|c|c|c|c|}
\hline \multirow[t]{2}{*}{ Temperature (K) } & \multicolumn{2}{|c|}{ Langmuir } & \multicolumn{4}{|c|}{ Freundlich } & \multicolumn{3}{|r|}{ Temkin } \\
\hline & $q$ & $\kappa_{L}$ & $\mathbf{R}^{2}$ & K & $n$ & $\mathbf{R}^{2}$ & $a$ & $b$ & $\mathbf{R}^{2}$ \\
\hline \multicolumn{10}{|l|}{ MO } \\
\hline 303 & 492.6 & 72.9 & 0.983 & 256.9 & 7.8 & 0.914 & 215.4 & 54.1 & 0.927 \\
\hline 313 & 518.1 & 145.6 & 0.992 & 297.4 & 9.9 & 0.938 & 273.6 & 43.0 & 0.934 \\
\hline 323 & 529.1 & 185.9 & 0.999 & 311.9 & 9.4 & 0.946 & 288.7 & 47.6 & 0.961 \\
\hline \multicolumn{10}{|l|}{$C R$} \\
\hline 303 & 289.9 & 10.8 & 0.999 & 152.7 & 11.6 & 0.776 & 146.7 & 17.7 & 0.734 \\
\hline 313 & 295.9 & 12.1 & 0992 & 115.1 & 5.7 & 0.802 & 77.8 & 39.1 & 0.757 \\
\hline 323 & 301.2 & 15.1 & 0.984 & 87.9 & 4.3 & 0.969 & 41.3 & 43.5 & 0.718 \\
\hline
\end{tabular}

where $q$ is the maximum adsorption capacity of RAC $(\mathrm{mg} / \mathrm{g})$ and $K_{L}$ is the constant of Langmuir isotherm related to energy of adsorption.

The Freundlich isotherm is represented as (7) [40] follows:

$$
q_{e}=K \times \sqrt[n]{C_{e}}
$$

where $K$ and $n$ are the constants of the Freundlich isotherm.

The Tempkin isotherm is given as the following equation (8):

$$
q_{e}=a+b \ln \left(C_{e}\right)
$$

where $a$ and $b$ are the constants of Tempkin isotherm.

The calculated parameters according to three models are listed in Table 4. From the results, we can see that the Langmuir models fitted the results slightly better than the other two models and the values of $\mathrm{R}^{2}$ are greater than 0.98. Accordingly, the Langmuir isotherm can be used to describe the adsorption behavior to MO and CR dye

A

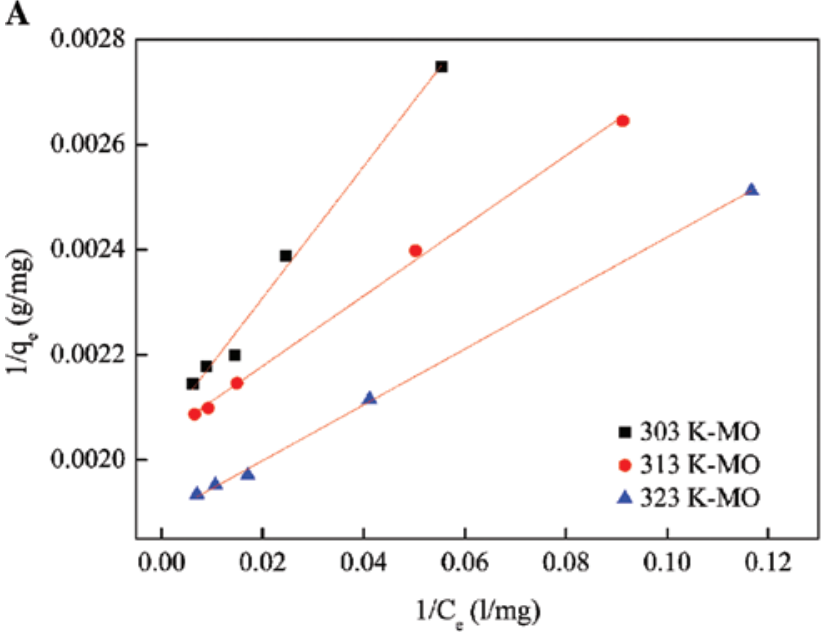

solution onto RAC. The Langmuir model suggests that the adsorption can be attributed to the monolayer coverage and the surface is uniform [41]. However, the data of Freundlich and Temkin models did not fit well with actual experimental data due to its low $\mathrm{R}^{2}$. The data were fitted with Langmuir isotherm as shown in Figure 10.

Table 5 summarizes the maximum adsorption capacity of the MO and CR dye solution onto different adsorbents with previous studies. From Table 5, it can be established that the RAC regenerated from the SMC exhibited much higher adsorption capacity, and the maximum MO and CR adsorption capacities were 529 and $301 \mathrm{mg} / \mathrm{g}$, confirming that the microwave and ultrasonic spray-assisted method was beneficial to the regeneration.

\subsection{Thermodynamic studies}

The thermodynamic studies of the adsorption of MO and CR onto RAC were carried out to reveal the possible mechanism [50]. The thermodynamic parameters were

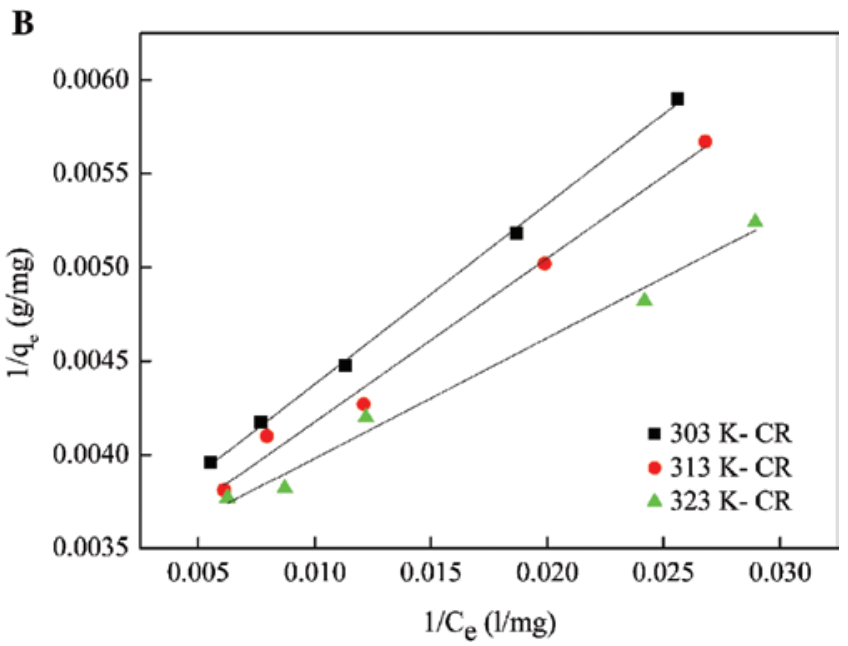

Figure 10: The experimental data fitting analysis by Langmuir isotherm for MO (A) and CR (B) dye solution at $303 \mathrm{~K}, 313 \mathrm{~K}, 323 \mathrm{~K}$. 
Table 5: The comparison of the maximum adsorption capacities of $M O$ and CR onto the different adsorbents.

\begin{tabular}{llrr}
\hline Adsorbents & Dyes & $\begin{array}{c}\text { Maximum adsorption } \\
\text { capacity (mg/g) }\end{array}$ & Reference \\
\hline RAC regenerated from SMC & MO & 529 & This work \\
Activated carbon of lignin & MO & 300 & {$[42]$} \\
Activated carbon of phragmites australis & MO & 238 & {$[43]$} \\
Activated carbon from date pits & MO & 434 & {$[46$} \\
commercially activated carbon & MO & 301 & {$[45]$} \\
RAC regenerated from SMC & CR & 105.4 & This work \\
Activated carbon from date pits & CR & 47.2 & {$[46]$} \\
Activated carbon from guava leaf & CR & 2.2573 & {$[47]$} \\
Activated carbon of olive stones & CR & 136.4 & {$[48]$} \\
Activated carbon from peanut shell & CR & & {$[49]$} \\
\hline
\end{tabular}

estimated from the Langmuir constants $\left(K_{L}\right)$. The change in Gibbs free energy $\left(\Delta G^{\circ}\right)$, enthalpy energy $\left(\Delta H^{\circ}\right)$ and the entropy change $\left(\Delta S^{\circ}\right)$ are calculated from the following equations (9-11):

$$
\begin{gathered}
\Delta G^{\theta}=-R T \ln K_{L}, \\
\Delta G^{\theta}=\Delta H^{\theta}-T \times \Delta S^{\theta}, \\
\log K_{L}=\frac{\Delta S^{\theta}}{2.303 R}-\frac{\Delta H^{\theta}}{2.303 R T},
\end{gathered}
$$

where $R$ is the gas constant $(8.314 \mathrm{~J} / \mathrm{mol} / \mathrm{K})$, and $T$ is the temperature in Kelvin $(K)$.

The slopes and intercepts of the plot of $\ln K_{L}$ versus $1 / T$ were employed to calculate the values of $\Delta S^{\theta}$ and $\Delta H^{\theta}$ (Figure 11). The thermodynamic parameters are listed in Table 6. It can be observed that the values of $\Delta G^{\theta}$ were negative for all temperatures and became more negative as the temperature increased, indicating that the process
Table 6: The thermodynamic parameters for adsorption of the MO and CR dye solution onto RAC.

\begin{tabular}{lrcr}
\hline Temperature (K) & $\Delta \boldsymbol{G}^{\boldsymbol{\theta}}(\mathrm{kJ} / \mathrm{mol})$ & $\Delta \boldsymbol{S}^{\boldsymbol{\theta}}(\mathrm{J} / \mathrm{mol} / \mathrm{K})$ & $\Delta \boldsymbol{H}^{\boldsymbol{\theta}}(\mathrm{kJ} / \mathrm{mol})$ \\
\hline MO & & & \\
303 & -10.8 & 160.4 & 38.2 \\
313 & -12.9 & & \\
323 & -14.1 & & \\
CR & & & \\
303 & -14.3 & 52.3 & \\
313 & -14.8 & & \\
323 & -15.3 & & \\
\hline
\end{tabular}

was endothermic and spontaneous [51]. It also explained that the high temperature would promote the extent of adsorption by decreasing the viscosity of the solution, which accelerate the mass transfer rate [52]. Moreover, the values of $\Delta H^{\theta}$ and $\Delta S^{\theta}$ were positive for RAC, suggesting that the endothermic nature of the adsorption and an increase in randomness at the solid-liquid interface [53].
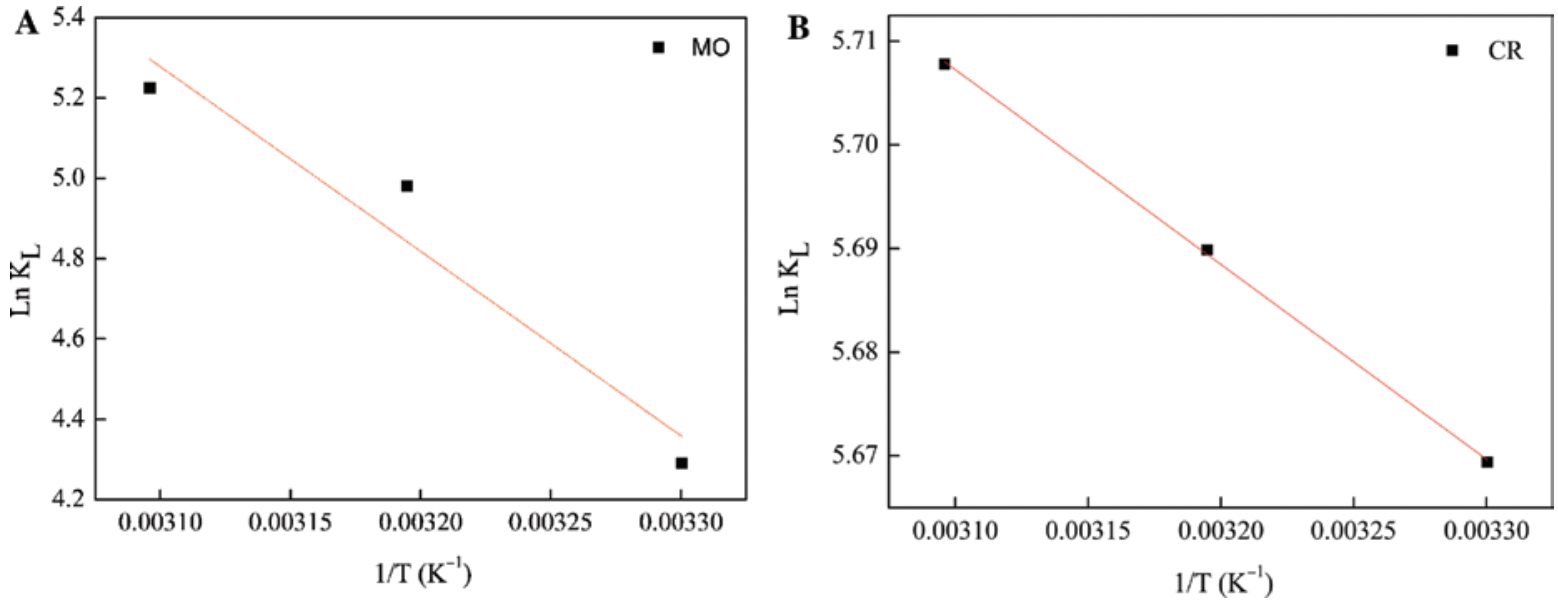

Figure 11: The thermodynamic study of adsorption of $M O(A)$ and $C R(B)$ dye solution. 


\section{Conclusions}

SMC was regenerated by using the microwave and ultrasonic spray-assisted method. The optimal regeneration conditions could be determined as the regeneration temperature of $900^{\circ} \mathrm{C}$ and regeneration time of $60 \mathrm{~min}$, for which the $\mathrm{MB}$ value was $210 \mathrm{mg} / \mathrm{g}$ and the specific surface area of RAC was as high as $801 \mathrm{~m}^{2} / \mathrm{g}$. The mercury content of RAC was reduced to $0.46 \mathrm{mg} / \mathrm{l}$. RAC has been confirmed to be a good adsorbent for the removal of the MO and CR dye solution. The kinetic data and adsorption isotherm fitted well with pseudo second-order and Langmuir isotherm, and the maximum MO and CR adsorption capacities were 529 and $301 \mathrm{mg} / \mathrm{g}$, respectively. The thermodynamic results indicated that the adsorption process was spontaneous and endothermic. Therefore, the SMCs regenerated by microwave and ultrasonic spray method can be used as a potential adsorption material for dye wastewater treatment.

Acknowledgments: This work was supported by the National Science Fund for Excellent Young Scholars of China (Grant no. 51522405).

\section{References}

[1] Li X, Wang Y, Kang L, Zhu M, Dai B. J. Catal. 2014, 311, 288-294.

[2] Zhang J, Liu N, Wei L, Dai B. Front. Chem. Sci. Eng. 2011, 5, 514-520.

[3] Wang F, Wang L, Wang J, Zhao Y, Wang Y, Yang D. React. Kinet. Mech. Catal. 2015, 114, 725-734.

[4] Liu C, Peng J, Ma AY, Zhang LB, Li J. J. Hazard. Mater. 2016, 322, 325-333.

[5] Gennadios A, Hanna MA, Kurth LB. Poultry and Seafoods: A Review, LWT 1997, 30, 337-350.

[6] Wei X, Shi H, Qian W, Luo G, Jin Y, Wei F. Ind. Eng. Chem. Res. 2009, 48, 128-133.

[7] Zhang H, Dai B, Li W, Wang X, Zhang J, Zhu M, Gu J. J. Catal. 2014, 316, 141-148.

[8] Yang T. China Plastics 2008, 22, 1-8.

[9] Li XY, Li P, Pan XL, Ma H, Bao XH. Appl. Catal. B Environ. 2017, 210, 116-120.

[10] Hutchings GJ, Grady DT. Appl. Catal. 1985, 16, 411-415.

[11] Hylander LD, Goodsite ME. Sci. Total Environ. 2006, 368, 352-370.

[12] Sonne C, Dietz R, Leifsson PS, Asmund G, Born EW, Kirkegaard M. Environ. Health 2007, 6, 11.

[13] Zhang XY, Wang QC, Zhang SQ, Sun XJ, Zhang ZS. J. Hazard. Mater. 2009, 168, 1575-1580.

[14] Randall P, Chattopadhyay S. J. Hazard. Mater. 2014, 114, 211-223.

[15] Xu X, He H, Zhao J, Wang B, Gu S, Li X. Chinese J. Chem. Eng. 2017, 25.

[16] Li X, Pan X, Yu L, Ren P, Wu X, Sun L, Jiao F, Bao X. Nat. Commun. 2014, 5, 3688.
[17] Bing JL, Cheng Z. Polyvinyl Chloride 2012, 40, 1-7.

[18] Liu C, Peng JH, Zhang LB, Wang SX, Ma AY. Chinese J. Chem. Eng. 2018, 26, 364-327.

[19] Shah IK, Pre P, Alappat BJ. J. Taiwan Inst. Chem. Eng. 2014, 45, 1733-1738.

[20] Lin G, Cheng S, Wang S, Hu T, Peng JH, Xia HY, Jiang F, Li S, Zhang LB. Catalysis Today 2017, In press.

[21] Ledesma B, Román S, Sabio E, Álvarez-Murillo A. J. Supercrit. Fluids 2015, 104, 94-103.

[22] Sun Y, Zhang B, Zheng T, Wang P. Chem. Eng. J. 2017, 320, 264-270.

[23] Yao S, Zhang J, Shen D, Rui X, Gu S, Ming Z, Liang J. J. Colloid Interface Sci. 2016, 463, 118.

[24] Ma S, Li Z, Ma J, Chai F, Zhu S. J. Environ. Chem. Eng. 2015, 3, 1312-1319.

[25] Peng L, Ismael ZM, Zhang WB, Yuan SH, Man T, Wang K, Bao JG. Chem. Eng. J. 2012, 195-196, 339-346.

[26] Cheng S, Wu J, Xia HY, Peng JH, Wang SX, Zhang LB. Desalin. Water Treat. 2012, 4, 1-11.

[27] Ania CO, Menéndez JA, Parra JB, Pis JJ. Carbon 2004, 42, 1383-1387.

[28] Georgin J, Dotto GL, Mazutti MA, Foletto EL. J. Environ. Chem. Eng. 2016, 4, 266-275.

[29] Shu JH, Cheng S, Xia HY, Zhang LB, Peng JH, Li CY, Zhang SZ. RSC Adv. 2017, 7, 14395-14405.

[30] Lu X, Jiang J, Sun K, Wang J, Zhang Y. Mar. Pollut. Bull. 2014, 78, 69-76.

[31] Ghaedi M, Nasab AG, Khodadoust S, Sahraei R, Daneshfar A. J. Ind. Eng. Chem. 2015, 21, 986-993.

[32] Dou J, Yu J, Tahmasebi A, Yin F, Gupta S, Li X, Lucas J, Na C, Wall T. Fuel Process. Technol. 2015, 135, 187-194.

[33] Vernadakis A. Zeitschrift Für Chemie Und Industrie Der Kolloide 1907, 2, 15.

[34] Albadarin AB, Mangwandi C, Al-Muhtaseb AAH, Walker GM, Allen SJ, Ahmad MNM. Chem. Eng. J. 2012, 179, 193-202.

[35] Ho YS, Mckay G. Process Saf. Environ. Prot. 1999, 77, 165-173.

[36] Saeidi N, Parvini M, Niavarani Z. J. Environ. Chem. Eng. 2015, 3, 2697-2706.

[37] Alothman ZA, Habila MA, Ali R, Ghafar AA, Hassouna ED. Arab. J. Chem. 2014, 7, 1148-1158.

[38] Da SLV, López-Sotelo JB, Correa-Guimarães A, Hernández-Navarro S, Sánchez-Báscones M, Navas-Gracia LM, Martín-Ramos P, Martín-Gil R. J. Environ. Manag. 2015, 155, 67-76.

[39] Lebron I, Suarez DL, Alberto F. Soil Sci. Soc. Am. J. 1994, 58, 1753-1762.

[40] Gong J, Wang X, Shao X, Yuan S, Yang C, Hu X. Talanta 2012, 101, 45-52.

[41] Ghaedi M, Ghaedi AM, Mirtamizdoust B, Agarwal S, Gupta VK. J. Mol. Liq. 2016, 213, 48-57.

[42] Mahmoudi K, Hamdi N, Kriaa A, Srasra E. Russ. J. Phys. Chem. A 2012, 86, 1294-1300.

[43] Chen SH, Jian Z, Zhang CL, Yue QY, Yan L, Chao L. Desalin. Water Treat. 2010, 252, 149-156.

[44] Mahmoudi K, Hosni K, Hamdi N, Srasra E. Korean J. Chem. Eng. 2015, 32, 274-283.

[45] León G, García F, Miguel B, Bayo J. Desalin. Water Treat. 2016, 57, 17104-17117.

[46] Belhachemi M, Addoun F. Desalin. Water Treat. 2012, 37, 122-129. 
[47] Ojedokun AT, Bello OS. Appl. Water Sci. 2017, 7, 1965-1977.

[48] Najar-Souissi S, Ouederni A, Ratel A. J. Environ. Sci. 2005, 17, 998-1003.

[49] Lawal I A, Chetty D, Akpotu So, Moodley B. Environ. Nanotechnol. Monit. Manage. 2017, 8, 83-91.

[50] Bulut Y, Aydın H. Desalination 2006, 194, 259-267.
[51] Li CY, Xia HY, Zhang LB, Peng JH, Cheng S, Shu JH, Zhang SZ. Res. Chem. Intermediat. 2017, 44, 1-20.

[52] Gautam PK, Saroj RS, Pandey JD. Proc. Natl. Acad. Sci. India 2015, 85, 35-39.

[53] Gautam PK, Gautam RK, Banerjee S, Lofrano G, Sanroman MA, Chattopadhyaya MC, Pandey JD. J. Environ. Chem. Eng. 2015, 3, 2560-2568. 